\title{
Globalization, Culture, and Development: Concepts, Clarifications, and Concerns
}

\author{
Ashley E. Maynard ${ }^{a} \quad$ Nandita Chaudhary ${ }^{b}$ \\ a University of Hawaii, Honolulu, HI, USA; ${ }^{b}$ University of Delhi, New Delhi, India
}

\section{Keywords}

Globalization · Culture · Development · Mixed methods · Intervention

\begin{abstract}
Between the time this volume was conceptualized and its publication, the world has seen dramatic changes as a consequence of the COVID-19 pandemic, changes that have directly impacted international relations and globalization. Because this issue of Human Development deals with insights and alternatives regarding globalization, culture, and development, the consequences of the pandemic are linked to the presentation of four specific articles based on invited addresses given at the 2019 Jean Piaget Society conference on the title topic. Beginning with this article, this volume aims to explore five themes: multiple pathways of development; the importance of understanding context for understanding development; using mixed methods; implications for interventions; and implications for how to engage people in diverse societies, even as those societies are changing.
\end{abstract}

(C) 2021 S. Karger AG, Basel
As we write this article, we are in the midst of a global pandemic. Demonstrating the ways that people of the world relate to each other, a novel coronavirus, labeled COVID-19, with a high infection and mortality rate has made its way to more than 150 countries. In addition to the serious impact the pandemic has had on relationships between countries, a look at how people in different countries have managed the virus reveals cultural patterns: how did countries deal with the impact? What strategies were attempted to deal with the crisis on health and the economy? Are citizens amenable to government suggestions to maintain healthy distance and to wear masks? How are the patterns of infection and economic destruction and recovery related to cultural values, norms, and practices? Furthermore, moments of crisis have been known to impact social processes in profound ways, sometimes even having the potential to result in serious social change. Though this special issue is not about the pandemic, acknowledging its potential impact and thinking about the spread and solutions to it provides examples of global, cultural, and developmental phenomena that are the topic of the articles in this special issue, namely pathways of development and their outcomes, the fluidity of development, the need to examine context in meaningful ways, the effectiveness of interventions, coloniality in social relations and practices, and the importance of co-constructing and sharing knowledge.

\begin{tabular}{|c|c|c|}
\hline $\begin{array}{l}\text { karger@karger.com } \\
\text { www.karger.com/hde } \\
\text { Karger } \%\end{array}$ & (C) 2021 S. Karger AG, Basel & $\begin{array}{l}\text { Ashley E. Maynard } \\
\text { University of Hawaii } \\
2530 \text { Dole Street, Sakamaki C-400 } \\
\text { Honolulu, HI } 96822 \text { (USA) } \\
\text { amaynard@ hawaii.edu }\end{array}$ \\
\hline
\end{tabular}


Humans develop along cultural pathways, the variety of which leads to different outcomes and responses to environmental and social pressures. The human newborn's ability to adapt to any cultural place on Earth demonstrates the flexibility and resilience of the human system. Development in infancy and after also demonstrates fluidity - humans change and adapt to changes in the settings they inhabit, they innovate, they migrate to new settings, they change their habits and points of view with input from new information or ideologies.

Researchers who make central the study of cultural aspects of development tend to have a deep understanding of the relationship between contexts and developmental pathways. Attention to context, really understanding the influence of the surrounding environmental and social factors on development, is essential in the developmental study of globalization.

Several aspects of cultural contact, or sharing across cultural groups, have implications for a globalizing developmental science. Making culturally appropriate interventions, understanding coloniality and processes of decoloniality, and co-constructing and sharing knowledge are all essential in a globalizing developmental science that examines phenomena of globalization, culture, and development. Culturally appropriate interventions require understanding the cultural place and the people they are meant to serve. Part of understanding many cultural settings means recognizing the influence of colonialization. But in this issue, we aim to establish a research practice and value to go beyond colonialization to decolonialization in order to understand cultural groups in their own right. Ultimately, co-constructing and sharing knowledge are required for a valid, engaged, and robust global developmental science.

\section{Globalization and Threats to Human Development}

The movement of COVID-19 around the world demonstrated that people are on the move across the world more than ever before. Referring to the enhanced interaction between and mixing of individuals, groups, companies, and governments around the world, the term "globalization" has tacitly implied increased homogeneity, both in ways of living and resources used. Market forces are believed to be pushing us to buy similar things, do similar activities, and live in similar ways. Technology and transportation have speeded up these exchanges and the spread of ideas between societies, although the direction of technology transfer is assumed as mostly moving from the wealthy West to the
Global South as a project of neocolonialism. Globalization is thus both the "compression of the world and the intensification of the consciousness of the world as a whole" (Robertson, 1992, p. 8), and Appadurai (1996), an expert on globalization, argues that the central problem of these increased global interactions is the tension between cultural homogenization and cultural heterogenization. Furthermore, the interaction between the global and local prompts the attention at both sides of the equation: the global emerging from the local and vice versa (Bhatia, 2018).

The threat of a "global epidemic of sameness" is real, and it can carry away entire human languages, destroy domesticated food crops, and kill off entire species. The havoc caused by this view of the human-environment interface is the cause for our balance with nature to become tenuous. "The fallout isn't merely an assault to our aesthetic or even ethical values" (Montenegro \& Glavin, 2015 , p. 1). There is a serious threat to diversity in biological as well as cultural spheres, and the disappearance of ethnic diversity is closely linked with the disappearance of biodiversity (Maffi \& Woodley, 2012). This potential curtailment and intolerance of "other" ways of living are manifestations of ethnocentrism and have far-reaching consequences, some of which are not possible to imagine at the outset. When social change is attempted, whether within migrating populations, international aid or even educational institutions, the intended impact for "help" is couched in a discourse of "development," which has the connotation of improvement, though such endeavors may not lead to improvement for the people being helped. In a globalized human developmental science, we have our attention not only on the course of developmental change of people, but how people adapt to changes in their environments, including changes brought by globalizing influences mentioned above.

In this special issue, although we adopt the meaning of globalization as intensified engagement between people and institutions around the world, the papers demonstrate how this inevitability (of greater exchange) can be advanced without the loss of diversity with a special eye on how to aim for unity within diversity in developmental science. How can we proceed with an idea of a world that does not collapse into a narrow version of an imagined society with uniform ways and means of living, but one that embraces difference as a core principle rather than an irksome problem? The challenge for developmental science is to integrate findings from a variety of cultural settings undergoing varying degrees of change into a changing conception of what development itself entails. We have a great opportunity to do this because we are 
engaged in a global science of developmental change. We have the chance to make our theories, our methods, and our analyses and discussions of findings more valid more reflective of the truth about what it means to develop as a human being - precisely because sensitive theory and description of the developmental experience that includes more of us should lead us to a deeper understanding of the truth of what it means to develop.

The special issue recognizes Freire's (1994) words of caution:

... oneness in difference will be the only effective response of those forbidden to be, those prevented from living, to the ancient rule of the mighty: divide and conquer. Without unity in diversity, the so-called minorities could not even struggle, in the United States, for the most basic (and therefore the "least," if we may so say) rights, let alone overcome the barriers that keep them from "being themselves," from being "minorities for themselves," with one another and not against one another. (p. 123)

We need to understand that unless we embrace and even celebrate diversity in the human-environment (and therefore culture and development) interface, our way of life, in fact the world as we know it, will be under threat. In fact, this pandemic has further underscored the importance of seriously reviewing our stance on the humanenvironment interface and its study. As the author Arundhati Roy (2020) writes, the pandemic is a portal:

$[\mathrm{U}]$ nlike the flow of capital, this virus seeks proliferation, not profit, and has, therefore, inadvertently, to some extent, reversed the direction of the flow. It has mocked immigration controls, biometrics, digital surveillance and every other kind of data analytics, and struck hardest - thus far - in the richest, most powerful nations of the world, bringing the engine of capitalism to a juddering halt. Temporarily perhaps, but at least long enough for us to examine its parts, make an assessment and decide whether we want to help fix it, or look for a better engine. The mandarins who are managing this pandemic are fond of speaking of war. They don't even use war as a metaphor, they use it literally ... Whatever it is, coronavirus has made the mighty kneel and brought the world to a halt like nothing else could. Our minds are still racing back and forth, longing for a return to "normality," trying to stitch our future to our past and refusing to acknowledge the rupture. But the rupture exists. And in the midst of this terrible despair, it offers us a chance to rethink the doomsday machine we have built for ourselves. Nothing could be worse than a return to normality. Historically, pandemics have forced humans to break with the past and imagine their world anew. This one is no different. It is a portal, a gateway between one world and the next. We can choose to walk through it, dragging the carcasses of our prejudice and hatred, our avarice, our data banks and dead ideas, our dead rivers and smoky skies behind us. Or we can walk through lightly, with little luggage, ready to imagine another world. And ready to fight for it.

\section{Understanding Globalization and Human Development: Theoretical, Methodological, and Analytical Approaches}

There is no one way to develop, and there is no one way to solve our problems. There is no one way to help or intervene. There is no one way that people adapt to their worlds - even the process of development itself may be changed by the child's or person's ability to adapt to settings and to changes in those settings. The articles in this special issue present new ideas in theoretical, methodological, and analytical approaches that we hope will help shift the conversation about how developmental science must consider the lived experience of people across the world and the findings coming in from those diverse settings. The papers help to set a standard for culturally appropriate interventions, including schooling, as well as for understanding the ways in which children and their families approach the world in order to find their way in it. The four articles in this special issue frame critical issues in the study of globalization, culture, and development. Specifically, the articles in this special issue address four issues in the study of human development: multiple pathways of development; the understanding of context and the importance of that for understanding development; implications for interventions; and implications for how to engage people in diverse societies, even as those societies are changing.

In the first article, Katie Silva and Barbara Rogoff draw on insights from developmental and cultural psychology and anthropology to examine the cultural logic involved in instructional ribbing, which in their data come from mothers who make mock insults, empty threats, and ironic comments to children in the course of activities. In mainstream society, such teasing may be regarded critically, but there has been little research examining its cultural logic. Ethnographic studies indicate that this is a valued mode of helping children work out an understanding of reasons that they should share and cooperate with others, in a variety of nondominant communities including Mexican-heritage, African American, and Inuit (e.g., Eisenberg, 1986; Goodwin, 1990; Briggs, 1998). Silva and Rogoff show how instructional ribbing is related to cultural valuing of autonomous learning during social endeavors, by giving children cues in context, rather than explaining rules, to encourage sharing and collaboration. This cross-disciplinary paper provides an example of how developmental scientists can use new interpretive lenses to understand a cultural phenomenon and its place in development.

In the second article, Nandita Chaudhary reimagines human developmental science in order to better repre- 
sent and address global concerns. Social justice and inclusion are important principles in the drive towards mutual respect, human dignity, and cultural diversity. Furthermore, the process and outcomes of globalization can, in fact, provide us with greater opportunities for advancement towards embracing diversity and pluralism rather than sameness. Chaudhary shows how intensified exchanges among the social sciences challenge the former world order that emerged from the impact of colonization, modernization, and industrialization. As we learn more about each other, domination and imperialism are no longer justifiable, and there is an increased movement towards expanding the base of the social sciences (samples, methods, interpretations) on ethical grounds. There is sufficient reason to believe that the bulk of the social sciences, especially psychology, is based on limited samples, and relatively narrow methods, leaving out entire cultures from the conversation about what constitutes the discipline. Chaudhary opens a conversation about a new way forward for developmental science.

In the third article, Sunil Bhatia sheds light on the universalizing power and the colonizing dimensions of Euro-American psychology and human development. $\mathrm{He}$ integrates insights from postcolonial, narrative and cultural psychology to ask how Euro-American scientific psychology becomes the standard bearer of psychology around the world, whose stories get told, what it means to develop, what knowledge is considered as legitimate, and whose lives are considered central to the future of human development. Urban Indian youth represent one of the largest segments of youth population from across the world and yet remain so utterly invisible in theories of human development. Bhatia adopts a decolonizing framework to examine: (a) how specific Euro-American psychological discourses of self and identity are now part and parcel of the workforce in emerging neoliberal global economies such as India; (b) how particular class identities shape youth narratives about globalization and "Indianness" generally, as well as specific stories about self and identity in contexts of work, poverty, and culturally hybrid identity practices. Bhatia articulates an alternative vision of psychology and human development in which questions of social justice and equality are seen as central to its mission. He argues that concepts of "development" and "culture" need to be reframed and understood within transnational connections and asymmetrical intersections of the global-local dynamic.

In the fourth article, Robert Serpell presents a perspectivist theoretical account of cross-cultural communication, with some worked examples of bridging, coordina- tion and fusion. He outlines the implications of this approach for understanding historical change, and for retrospective psychological integration of personal development in later stages of life. He uses the case of an African setting for discussing for socioculturally responsive programming of early childhood care and education. His article argues that participatory appropriation of new practices requires strong linkages between old and new understandings, that successful co-construction by diverse stakeholder groups requires both common ground and agreed modes of interaction, that sustainable policy requires institutional transformation, and that psychological science has better prospects of impacting policy if it is embedded in a multidisciplinary framework.

As a whole, these articles show how a focus on globalization can suggest some fruitful future directions for psychology: greater engagement with other social sciences; the abandonment of neocolonialism; with the diminishing of community life, the adoption of what economist Rajan (2019) labels "inclusive localism" for strengthening society; and other future directions for a culturally grounded understanding of development in the context of a globalizing world.

Following the four empirical articles are commentaries by two other leading authorities in the global study of development: Cynthia García Coll and Tom Weisner. In their commentaries, both García Coll and Weisner call for steps beyond integration of theoretical and methodological approaches across fields. They call for paradigm shifts in the ways developmental science is approached - not just cultural, cross-cultural, or global studies, but all studies of human development. García Coll calls for reformulations of our theories to include contextual influences and the questioning of the assumptions of universals that have been considered standards in human development against which all groups are measured. Weisner points to the now long and rich history of research that has examined dozens of societies with contextually minded theories and methods, situating this special issue in the oeuvre of related theoretical and empirical work that has appeared in Human Development since at least the 1960s (see LeVine, 1966), continuing through the 2000s to today.

The issue concludes with our own look at how developmental science in a globalizing world can be made to be more inclusive and more valid, as well as the challenges in meeting these goals. Forces of globalization present an opportunity to examine our science critically and to move forward in more informed ways that we expect will lead to a more complete story and sharpened theories of what it means to develop in a changing world. 


\section{References}

Appadurai, A. (1996). Modernity at large: Cultural dimensions of globalization. University of Minnesota Press.

Bhatia, S. (2018). Decolonising psychology: Globalisation, social justice and youth identities. Oxford University Press.

Briggs, J. L. (1998). Inuit morality play: The emotional education of a three-year-old. Yale University Press.

Eisenberg, N. (1986). Altruistic cognition, emotion, and behavior. Erlbaum.
Freire, P. (1994). Pedagogy of hope: Reliving pedagogy of the oppressed. Continuum Publishing.

Goodwin, M. H. (1990). He-said-she-said: Talk as social organization among Black children. Indiana University Press.

LeVine, R. A. (1966). Toward a psychology of populations: The cross-cultural study of personality. Human Development, 9(1-2), 30-46. https://doi.org/10.1159/000270367

Maffi, L., \& Woodley, E. (2012). Biocultural diversity conservation. Earthscan. https://doi.org/ $10.4324 / 9781849774697$
Montenegro, M., \& Glavin, T. (2015, October 28). In defense of difference. Seed Magazine. http:// seedmagazine.com/content/article/in_defense_of_differencel

Rajan, R. (2019). The third pillar: How markets and the state leave community behind. Harper Collins.

Robertson, R. (1992). Globalization. SAGE.

Roy, A. (2020, April 3). The pandemic is a portal. Financial Times. https://www.ft.com/content/ 10d8f5e8-74eb-11ea-95fe-fcd274e920ca 